\title{
Is spatial autocorrelation an intrinsic property of territory size?
}

\author{
Mihai Valcu • Bart Kempenaers
}

Received: 25 July 2009/Accepted: 2 November 2009/Published online: 19 November 2009

(c) The Author(s) 2009. This article is published with open access at Springerlink.com

\begin{abstract}
In animals, competition for space and resources often results in territorial behaviour. The size of a territory is an important correlate of fitness and is primarily determined by the spatial distribution of resources and by interactions between competing individuals. Both of these determinants, alone or in interaction, could lead to spatial non-independence of territory size (i.e. spatial autocorrelation). We investigated the presence and magnitude of spatial autocorrelation (SAC) in territory size using Monte Carlo simulations of the most widely used territory measures. We found significant positive SAC in a wide array of competition-simulated conditions. A meta-analysis of territory size data showed that SAC is also a feature of territories mapped based on behavioural observations. Our results strongly suggest that SAC is an intrinsic trait of any territory measure. Hence, we recommend that appropriate statistical methods should be employed for the analysis of data sets where territory size is either a dependent or an explanatory variable.
\end{abstract}

Keywords Home range - Thiessen polygons . Dirichlet tessellation - Monte Carlo simulation . Bivariate kernel

Communicated by Janne Sundell.

Electronic supplementary material The online version of this article (doi:10.1007/s00442-009-1509-4) contains supplementary material, which is available to authorized users.

M. Valcu $(\square) \cdot$ B. Kempenaers

Department of Behavioural Ecology and Evolutionary

Genetics, Max Planck Institute for Ornithology,

Eberhard-Gwinner-Strasse, 82319 Seewiesen, Germany

e-mail: valcu@orn.mpg.de

\section{Introduction}

In animals, territorial behaviour is an important aspect of competition for space and for spatially distributed resources, and hence influences population regulation and reproductive dynamics (Gordon 1997; Makarieva et al. 2005). Correlational and experimental studies on many vertebrate taxa in a wide array of ecological contexts have shown a robust link between territory size and measures of individual fitness or fitness-related traits [e.g. reproductive success (Both and Visser 2000; Wilkin et al. 2006), offspring growth rate and parental and offspring survival (Both and Visser 2000), male heterozygosity (Seddon et al. 2004), male body size (Candolin and Voigt 2001; Vanpe et al. 2009), male age (Cavé et al. 1989), number of mates (Davies and Lundberg 1984; Vanpe et al. 2009)].

Two important factors have been suggested as determinants of territory size: the spatial distribution of resources (e.g. food, nest sites, females); and space partitioning resulting from interactions among neighbours (Adams 2001). Some studies showed a negative correlation between territory size and territory quality, whereby territory quality could in turn be predicted by characteristics of the habitat (Andrén 1990; Smith and Shugart 1987). This supports the hypothesis that territory size depends on the availability of resources, so that plentiful resources allow territories to be smaller. However, some correlational and experimental studies, mostly focusing on individuals with contiguous territories, failed to find a link between food abundance and territory size (reviewed in Adams 2001). The complementary hypothesis proposes that territory size is an outcome of interactions between contiguous neighbours (Adams 2001). This is supported by removal experiments which showed that territories expanded when 
neighbours were removed (Adams 1998; Both and Visser 2000; Candolin and Voigt 2001).

The two aforementioned determinants of territory size imply that territories that are closer together in space should be of similar size, either as a result of spatial heterogeneity in food availability (or another resource) occurring at a scale larger than that of the average territory, or as a result of space partitioning. This means that territory size cannot be considered an independent trait of one individual, that is, territory size will be spatially autocorrelated. Spatial autocorrelation (SAC), i.e. the degree of dependency among observations at a given spatial scale (Cressie 1993; Legendre 1993), is a well-recognized phenomenon in biogeography studies on species distributions and abundances (Dormann 2007). However, with the notable exception of population genetic studies investigating the spatial genetic structure of populations (Manel et al. 2003), the problem of SAC has been largely ignored in animal population ecology in general and in studies investigating territory size in particular.

If territory size is spatially autocorrelated, it raises the question whether the use of the classic statistical toolkit is appropriate for the analysis of datasets where territory size is either predictor or dependent variable. SAC can result in elevated type I error rates (Legendre et al. 2002), biased point estimates (review in Dormann 2007), and biases in model selection (Lennon 2000), and can thus lead to false conclusions.

In this paper we investigate the presence and magnitude of SAC in territory size, and the implications for statistical modelling. We assess the presence and the extent of SAC in territory size based on datasets obtained by three widely used territory models: Thiessen polygons (Adams 2001; Sibson 1980; hereafter "Thiessen territories"), kernel polygons (Worton 1989; hereafter "kernel territories") and territory mapping (Bibby et al. 2000; hereafter "mapped territories").

First, we use simulated Thiessen and kernel territories to show that SAC of territory size can occur in a wide range of contexts under both increased and relaxed competition. Second, we use published territory mapping data to show the importance of SAC in territory size in real animal populations. Our results suggest that small-scale positive SAC is, in many contexts, an intrinsic trait of territory size which may render the use of classic statistical tools inappropriate. We then discuss alternative statistical procedures that are more suitable for the analysis of datasets including territory size as a dependent or predictor variable.

\section{Materials and methods}

We used Monte Carlo simulation techniques to investigate SAC of territory size in different competition contexts.
Competition of neighbouring individuals is reflected: (1) in the spatial distribution of individuals, whereby increased competition results in an increased spatial regularity (Campbell 1992); and (2) in the strength and number of interactions at the territory boundaries whereby the degree of exclusion of the neighbours from the focal territory (i.e. level of competition) determines the amount of overlap between territories (Maher and Lott 1995). We therefore modelled the intensity of competition either by altering the spatial distribution of territory centres or by varying territory overlap (see below). Each Monte Carlo "experiment" was performed using a $10 \times 10$ flat surface starting with 150 territories.

To assess SAC of territory size we computed a widely used measure of SAC: Moran's I coefficient $\left(I_{\mathrm{M}}\right.$; Fortin and Dale 2005; Moran 1950). $I_{M}$ is comparable to a Pearson's correlation coefficient taking values between 0 and 1 in the case of positive SAC and between -1 and 0 in the case of negative SAC. The expected value of $I_{M}$ in the absence of SAC is negative but very close to zero for large enough sample sizes (Bivand et al. 2008).

\section{SAC in territory size under increased competition}

A preliminary simulation (Supplementary Material 1) showed that SAC of Thiessen polygons generated under complete spatial randomness (CSR) is only present at the scale of first-order neighbours (first-order neighbours have to share at least one boundary). Therefore, in the following simulation experiment we investigated the amount of SAC in Thiessen territory size of first-order neighbours under varying levels of competition.

Thiessen polygons - also known as Voronoi diagrams or Dirichlet tessellations (Aurenhammer 1991) —are used to describe the area of influence of each point (in this case territory centres), defined by a polygon encompassing the area closer to the target point than to any other point (Sibson 1980). More details on procedures to control for edge effects, to define neighbours and to compute Moran's $I$ are given in Supplementary Material 1. The spatial regularity of the territories, and thus competition, was monotonically increased by generating points through a simple sequential inhibition (SSI) process (Diggle et al. 1976). The SSI process is obtained by first generating a random (CSR) pattern, one event at a time and then excluding any new event that falls within distance $r$ of any previous events (Baddeley and Turner 2005). The inhibition radius $r$ was allowed to vary in the widest possible interval $(0,0.9)$ given the starting parameters. The effective sample size, after the edge effect correction, was $108 \pm 7$ (mean \pm SD) for small radii $(r<0.5)$ and decreased to $42 \pm 2$ for the largest possible radius $(r=0.90)$. The simulation was performed 1,000 times for 100 distinct $r$ values and 
confidence envelopes were constructed from Monte Carlo 95\% confidence limits computed for each $r$.

SAC in territory size under reduced competition

In the second simulation we investigated the level of SAC in territory size based on kernel territories. A kernel territory was constructed as follows. First, Thiessen polygons were constructed around territory centres simulated under a random pattern (CSR) and the boundary polygons eliminated (see Supplementary Material 1). Second, within each Thiessen polygon 50 points were simulated under CSR. The position of each point was altered by adding noise generated from a continuous uniform distribution $U(a, b)$ where $a$ and $b$ where randomly extracted from a sequence $(0, i, \ldots, N)$ of fixed length while $N$ was allowed to vary in the interval $(0,50)$ generating a vector of $100 \mathrm{~N}$ values. A kernel territory was estimated using a bivariate normal kernel (80\% utilization distribution; Worton 1989) for each set of 50 points. The utilization distribution is a bivariate probability function which gives the likelihood that an individual is found at a given location. Thus a kernel territory is defined as the minimum area in which an animal has a given probability of being located.

A monotonic increase in territory overlap, and thus a decrease in competition, was achieved by increasing the limits $(N)$ within which the noise added to the spatial coordinates of the points underlying the kernel territories was allowed to vary. The neighbourhood relations between kernel territories were established based on the initial Thiessen polygons. For each simulation, we used the same sample size and the same procedure to compute Moran's I as in previous simulations. The simulation was performed 1,000 times for each $100 \mathrm{~N}$ values and confidence envelopes constructed from Monte Carlo 95\% confidence limits computed for each $N$.

\section{Type I error rate}

We investigated the probability of rejecting a null hypothesis when in fact it is true (type I error rate) due to SAC in territory size by testing the correlation between territory size and a randomly generated independent variable $z$. We did this for three scenarios from the previous simulations chosen in the range of $I_{\mathrm{M}}$ found in the meta-analysis of mapped territories (see below): Thiessen territories under a random (CSR) pattern $\left(I_{\mathrm{M}}=0.31\right)$, Thiessen territories under increased competition (SSI with $r=1, I_{\mathrm{M}}=0.22$ ), and kernel territories under decreased competition (with $40 \%$ overlap, $I_{\mathrm{M}}=0.15$ ). The variable $z$ was initially generated independent of territory size from a standard normal distribution. Then, $z$ was transformed using a spatial autoregressive transformation (Bivand et al. 2008; Haining 1993) and the spatially autocorrelated variable $z^{\prime}$ was computed as $z^{\prime}=(I-\rho W)^{-1} z$ where $W$ is the row-standardized weights matrix corresponding to the simulated Thiessen territories, $\rho$ is the autoregressive parameter which is allowed to vary in the interval $(0,1)$ and $I$ is the identity matrix. The widely used Pearson correlation coefficient $r$ was computed for each chosen scenario and 100 independent $z^{\prime}$ values in the interval $(0$, 1). The simulation was repeated 1,000 times for each $\rho$ and the type I error rate, i.e. the proportion of cases where the null hypothesis was falsely rejected (for a significance level $\alpha=0.01$ ) was computed.

Meta-analysis of SAC based on data from published mapped territories

Using published data, we investigated SAC in territory size based on mapped territories. First, we performed full text searches using the keywords "territory map*" or "map of territor*" on bibliographic databases allowing for full text search: jstor (http://www.jstor.org/), bioone (http://www. bioone.org/) and ScienceDirect (http://www.sciencedirect. $\mathrm{com} /$ ). Second, we scanned the selected papers for maps of territories obtained via detailed observations of territorial behaviour of individually marked animals (colour-tagged individuals). We included only studies presenting maps of more than ten individuals and of territories not obviously constrained by the geography of the study site (e.g. territories mapped on a peninsula or a small stretch of suitable habitat). We found 14 studies which met these criteria. When a study presented multiple maps (i.e. more than one study site or season) we used the map with the highest number of territories (see Supplementary Material 2 for details on each study). All the maps were saved in a raster format and each territory was manually digitized and saved in a vector format.

Territory size was calculated for each mapped territory and $I_{\mathrm{M}}$ was computed at the level of first-order neighbours (with at least one common boundary) using a row-standardized weights matrix (Bivand et al. 2008). The combined effect size, for all 14 studies, was computed using DerSimonian and Laird's meta-analytical method for the estimation of random effects (DerSimonian and Laird 1986).

Software

All Monte Carlo experiments and analyses were performed with R 2.8.1 (http://www.r-project.org). The following add-on packages were used: spdep (Bivand 2008), meta (Schwarzer 2009), spatstat (Baddeley and Turner 2005), adehabitat (Calenge 2006). 


\section{Results}

Thiessen territories generated under CSR were positively spatially autocorrelated at the level of first-order neighbours $\left[I_{\mathrm{M}}=0.31,95 \%\right.$ confidence interval $(\mathrm{CI})=(0.19$, $0.43)]$ but were not different from the random expectation at larger spatial scales (Supplementary Material 1).

Significant SAC was present in the simulated Thiessen territories generated under increased competition (SSI) across the whole range of inhibition radii $r$, whereby the $I_{\mathrm{M}}$ decreased with increasing $r$ (Fig. 1). However, the decrease in $I_{\mathrm{M}}$ only started at a relatively large inhibition radius ( $r=0.25$; Fig. 1), suggesting that an increasing level of competition will minimally affect SAC. Even for the largest possible inhibition radius, the $\mathrm{SAC}$ was still positive and significant $\left[I_{\mathrm{M}}=0.22,95 \% \mathrm{CI}=(0.04,0.4)\right]$.

The level of SAC decreased with decreasing competition, that is, with increasing territory overlap, starting with a territory overlap of $15 \%$ (Fig. 2). Only at levels of territory overlap above $62 \%$ did $I_{M}$ become non-significant.

As expected, the type I error rate increased with increasing autocorrelation of the covariate $z^{\prime}$ for all three scenarios (Fig. 3). The error rate depends on the SAC in territory size: it is highest in the case of Thiessen territories

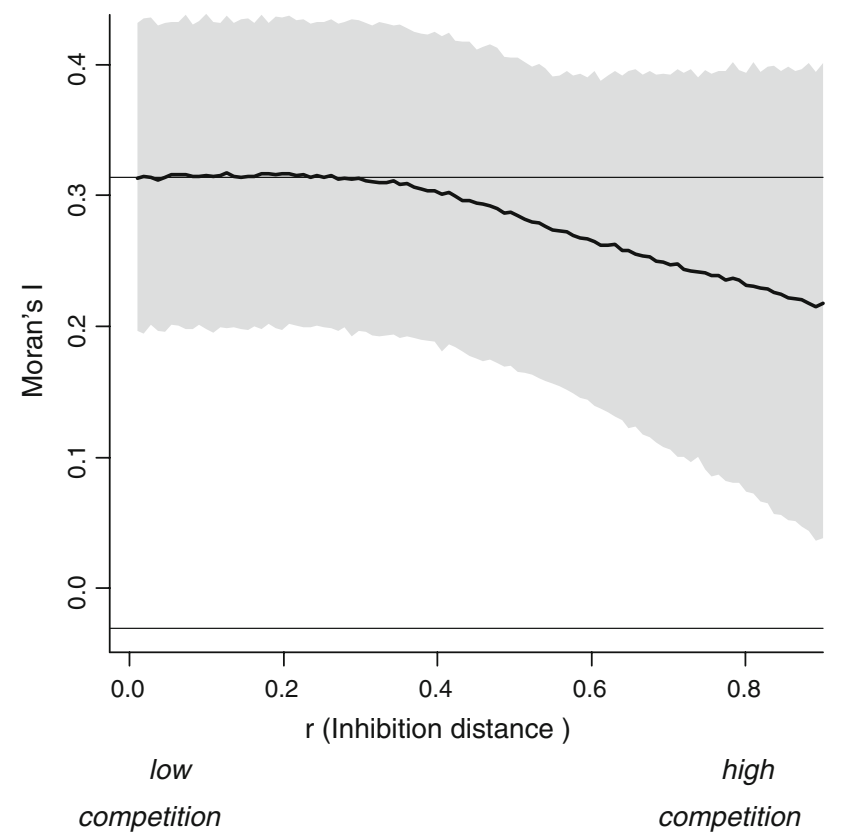

Fig. 1 Moran's $I$ coefficient $\left(I_{\mathrm{M}}\right)$ of Thiessen territory size at the scale of closest neighbours as a function of inhibition distance $(r)$ of a sequential spatial inhibition point process (see Materials and methods for details). The confidence envelope (grey area) represents simulated 95\% confidence limits. The upper thin horizontal line indicates the $I_{\mathrm{M}}$ of Thiessen territory size constructed from territory centres under complete spatial randomness. The lower thin horizontal line is the expected value of $I_{\mathrm{M}}$, under the null hypothesis of no autocorrelation, for the minimum sample size $(n=34)$

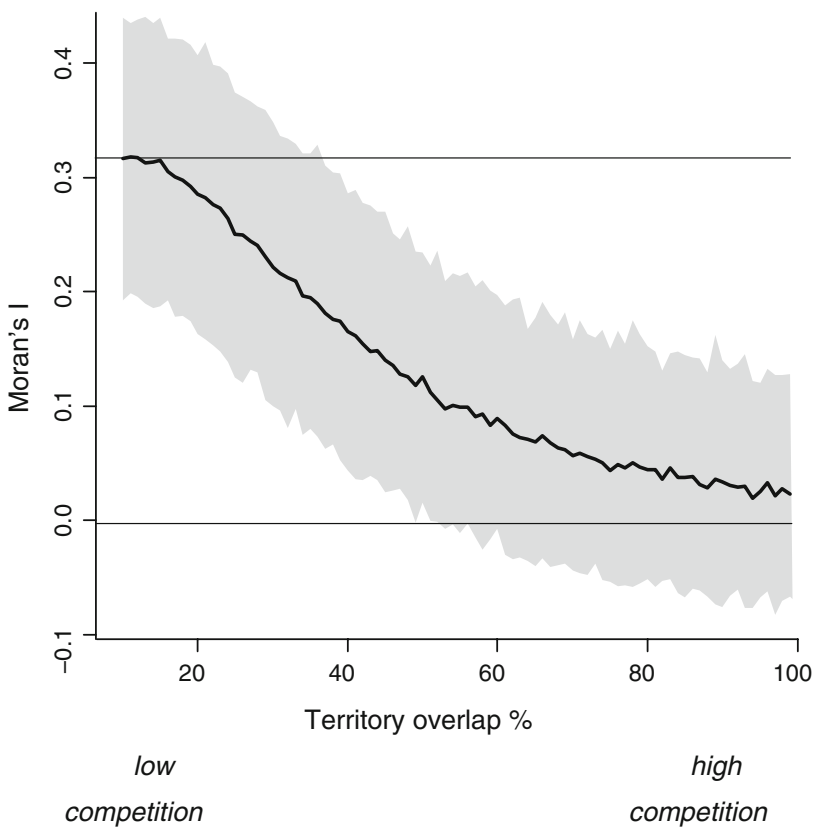

Fig. $2 I_{\mathrm{M}}$ of kernel territory size at the scale of closest neighbours as a function of territory overlap. The confidence envelope (grey area) represents simulated $95 \%$ confidence limits. The upper thin horizontal line shows the $I_{\mathrm{M}}$ of Thiessen territory size constructed from territory centres under complete spatial randomness. The lower thin horizontal line is the expected value of $I_{\mathrm{M}}$ under the null hypothesis of no autocorrelation

under CSR $\left(I_{\mathrm{M}}=0.31\right)$, intermediate for Thiessen territories under SSI $\left(I_{\mathrm{M}}=0.22\right)$ and lowest under kernel territories $\left(I_{\mathrm{M}}=0.15\right.$; Fig. 3$)$.

Positive SACs in territory size were found in most of the published studies with mapped territories. Only two out of the 14 studies showed a negative SAC, albeit not significantly different from zero; the other 12 studies exhibited a positive SAC ranging between $I_{\mathrm{M}}=0.09$ and 0.46 (Fig. 4; see also Supplementary Material 2). The overall combined effect size was $I_{\mathrm{M}}=0.19,95 \% \mathrm{CI}=[0.09,0.29]$, $P=0.0003$.

\section{Discussion}

\section{SAC of territory size}

SAC is a common property of all three territory models we investigated. We found small-scale positive SAC in simulated Thiessen and kernel territories and in the majority of published mapped territories. When SAC occurs both in territory size and in a covariate of territory size the Pearson correlation coefficient suffers from an inflated type I error rate.

We investigated SAC of territory size in a series of Monte Carlo experiments using Thiessen and kernel 
$\operatorname{lm}$

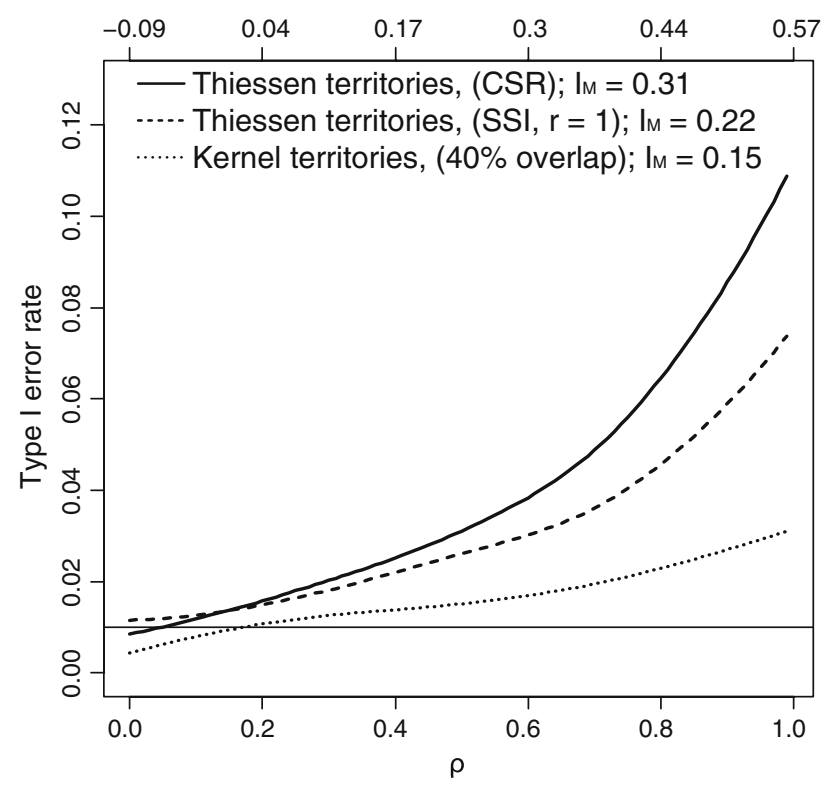

Fig. 3 Type I error rate for $\alpha=0.01$ (indicated by the thin horizontal line) of Pearson correlation coefficients for three classes of territory models as a function of the spatial autocorrelation coefficient $\rho$ of a simultaneous autoregressive process (spatially autocorrelated covariate). For comparison $I_{\mathrm{M}}$ is shown on the upper $x$-axis

territories, two commonly used territory models. The Thiessen polygon model and its variants were used in studies on aggressive behaviour (Adams 1998), on individual reproductive processes and on timing of breeding (Garant et al. 2005; Valcu and Kempenaers 2008; Wilkin et al. 2006). The Thiessen territory model assumes a central territory place (e.g. nest location), strong competition (i.e. sharp boundary) and a complete utilization of the available space. In contrast, the Kernel territory model (Fieberg 2007; Worton 1989) describes the territory of an animal in terms of probabilities using the concept of utilization distribution and does not require a fixed centre or full utilization of the available space.

The cause of SAC can be inherent or induced (Fortin and Dale 2005; Legendre et al. 2002). Inherent or true SAC appears as a result of the variable itself, while induced SAC [or "induced spatial dependence" (Legendre et al. 2002)] arises in response to exogenous factors (e.g. food, nest sites, mating partners), which are themselves spatially autocorrelated. Boundary interactions between close neighbours can be seen as an inherent process leading to small-scale positive SAC in territory size. The Monte Carlo experiments showed that Thiessen territories exhibit inherent SAC, with estimates in the range of $I_{\mathrm{M}}=(0.22-$ 0.31) (Fig. 1), irrespective of whether their underlying spatial distribution is random (CSR) or increasingly uniform (SSI). Any empirical study using Thiessen territories is therefore likely to suffer from SAC in territory size

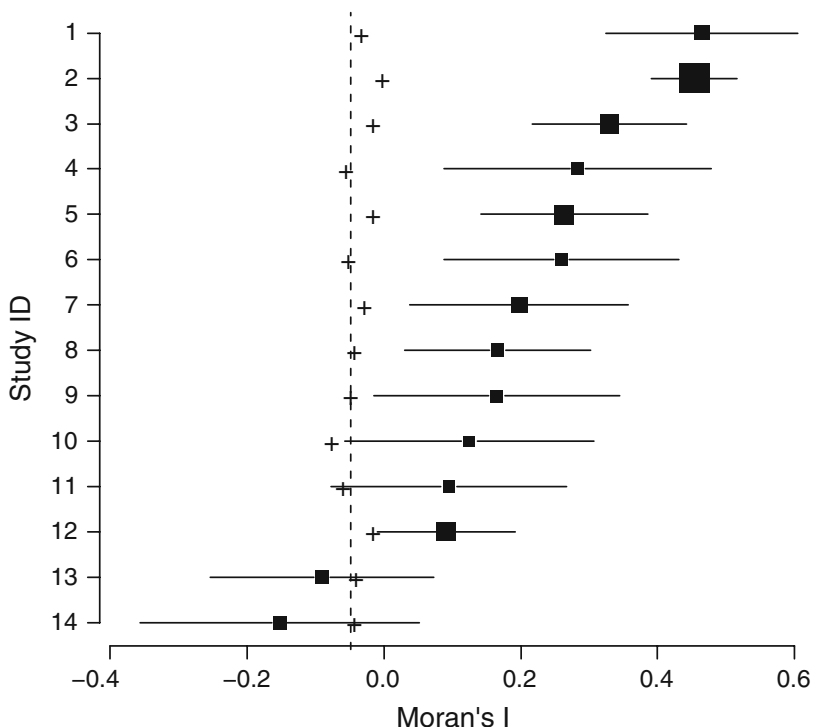

Fig. $4 I_{\mathrm{M}}$ at the scale of closest neighbours of mapped territory sizes. Data were obtained from published territory maps. Studies are ordered by their point estimates. The horizontal error bars show the $\mathrm{SD}$. The size of the squares is proportional to the square root of the sample size of each study. The dotted vertical line shows the median expected $I_{\mathrm{M}}$ for all studies, under the null hypothesis of no autocorrelation, whereas the crosses show the expected $I_{\mathrm{M}}$ for each study separately. 1 Breininger et al. (2006), 2 Heg et al. (2000), 3 Wortman-Wunder (1997), 4 Pedersen (1984), 5 Fort and Otter (2004), 6 Davies and Hartley (1996), 7 Tomiałojć and Lontkowski (1989), 8 de Ita and de Silva (2007), 9 Bourski and Forstmeier (2000), 10 Enoksson and Nilsson (1983), 11 Krebs (1970), 12 Watson and Miller (1971), 13 Broughton et al. (2006), 14 Ramsay et al. (1999) (see Supplementary Material 2 for details of each study)

estimates. For example, in a blue tit (Cyanistes caeruleus) population, the $I_{\mathrm{M}}$ of Thiessen territory area was $0.27 \pm 0.05$ (mean \pm SD) across 7 years of study [see (Valcu and Kempenaers 2008) for details on the study population].

Inherent SAC in territory size also appears when the more realistic kernel territory is used. Simulations of kernel territories showed that $I_{M}$ decreased quickly with increasing territory overlap (i.e. decreasing competition). However, SAC of territory size remained positive and significant for a large range of territory overlaps and only became non-significant at overlaps larger than $60 \%$ (Fig. 2).

We also investigated SAC in territory size based on published mapped territories using a meta-analytical approach. Territory mapping involves identification of an individual's positions and its territorial behaviour (e.g. boundary disputes, territory marking) and it is thus a very accurate territory model. We found positive SAC at small scale (close neighbours) in most of the mapped territory datasets included in the meta-analysis. The overall effect size $\left(I_{\mathrm{M}}\right)$ was 0.19 which is in the range of the $I_{\mathrm{M}}$ values obtained in the simulations. Two studies (Breininger et al. 
2006; Heg et al. 2000) had a relatively large $I_{M}$ of 0.46 and 0.44 respectively (Fig. 4). Interestingly, in both these studies (Breininger et al. 2006; Heg et al. 2000) territories are contiguous and situated in a qualitatively heterogeneous habitat leading to territories of very different qualities. We speculate that in those two studies a base level of inherent SAC resulting from inter-neighbour interactions is further increased by an extrinsic spatially autocorrelated variable. The $I_{M}$ of the remaining studies that showed a positive SAC (ID 3-12) was in the range (0.10-0.33) which could have resulted solely from interactions between individuals.

\section{Type I error rate}

The simulations show that SAC of territory size unavoidably inflates the probability of type I errors. In accordance with two previous studies (Legendre et al. 2002; Lennon 2000) we found that the type I error rate of the Pearson correlation coefficient increases with the SAC of the covariate. When SAC of the covariate is zero or very small, the significance level of the Pearson correlation is correct. However, once SAC in the covariate increases, the rate of type I error increases rapidly with the strength of the SAC. For example, for randomly distributed (CSR) Thiessen territories we found that the type I error rate was tenfold higher when SAC of the covariate $\left(I_{\mathrm{M}}\right)$ reached 0.50 (Fig. 3). Even when SAC of territory size is relatively small $\left(I_{\mathrm{M}}=0.15\right)$, as in the largely overlapping kernel territories, the type I error rate is still inflated when SAC of the covariate is relatively large (Fig. 3).

\section{Methods to account for SAC of territory size}

Fortunately, a wide range of statistical tools are available to model SAC (e.g. Bivand et al. 2008; Cressie 1993; Fortin and Dale 2005) and many more are being tested or are under development (Griffith and Peres-Neto 2006; Kato 2008; Kissling and Carl 2008). In the Supplementary Material 3 we point to some widely available spatial analysis tools used in modelling SAC and highlight some of the particularities of modelling SAC of territory size. The source code of a working example written in $\mathrm{R}$ (http://www.r-project.org) is also available in Supplementary Material 3.

\section{Conclusion}

SAC is a common feature of three widely used territory models: Thiessen polygons, bivariate kernel polygons and mapped territories based on behavioural observations. When territory size results from interactions between neighbours, such that the available space is partitioned between individuals, SAC is probably an intrinsic universal trait of any territory measure. Because SAC increases the risk of type I errors, classic statistical tools should be used with caution or alternative methods should be employed. This is particularly true when the covariates of territory size are themselves spatially autocorrelated, which will often be the case.

Acknowledgments We thank Pernilla Borgström for help with literature screening and digitizing and Holger Schielzeth for comments on the manuscript. We are grateful to three anonymous reviewers, whose comments helped to improve the manuscript.

Open Access This article is distributed under the terms of the Creative Commons Attribution Noncommercial License which permits any noncommercial use, distribution, and reproduction in any medium, provided the original author(s) and source are credited.

\section{References}

Adams ES (1998) Territory size and shape in fire ants: a model based on neighborhood interactions. Ecology 79:1125-1134

Adams ES (2001) Approaches to the study of territory size and shape. Annu Rev Ecol Syst 32:277-303

Andrén H (1990) Despotic distribution, unequal reproductive success, and population regulation in the jay Garrulus glandarius L. Ecology 71:1796-1803

Aurenhammer F (1991) Voronoi diagrams - a survey of a fundamental geometric data structure. ACM Comput Surv 23:345-405

Baddeley A, Turner R (2005) Spatstat: an R package for analyzing spatial point patterns. J Stat Softw 12:1-42

Bibby CJ, Burgess ND, Hill DA, Mustoe SH (2000) Bird census techniques. Academic Press, London

Bivand R (2008) spdep: Spatial dependence: weighting schemes, statistics and models. $\mathrm{R}$ package version 0.4-29 http://CRAN.R-project.org/package=spdep

Bivand R, Pebesma EJ, Gómez-Rubio V (2008) Applied spatial data analysis with R. Springer, New York

Both C, Visser ME (2000) Breeding territory size affects fitness: an experimental study on competition at the individual level. J Anim Ecol 69:1021-1030

Breininger DR, Toland B, Oddy DM, Legare ML (2006) Landcover characterizations and Florida scrub-jay (Aphelocoma coerulescens) population dynamics. Biol Conserv 128:169-181

Calenge C (2006) The package "adehabitat" for the R software: a tool for the analysis of space and habitat use by animals. Ecol Model 197:516-519

Campbell DJ (1992) Nearest-neighbour graphical analysis of spatial pattern and a test for competition in populations of singing crickets (Teleogryllus commodus). Oecologia 92:548-551

Candolin U, Voigt H-R (2001) Correlation between male size and territory quality: consequence of male competition or predation susceptibility? Oikos 95:225-230

Cavé AJ, Visser J, Perdeck AC (1989) Size and quality of the coot Fulica atra territory in relation to age of its tenants and neighbors. Ardea 77:87-98

Cressie NAC (1993) Statistics for spatial data. Wiley, London

Davies NB, Lundberg A (1984) Food distribution and a variable mating system in the Dunnock, Prunella modularis. J Anim Ecol 53:895-912 
DerSimonian R, Laird N (1986) Meta-analysis in clinical trials. Control Clin Trials 7:177-188

Diggle PJ, Besag J, Gleaves JT (1976) Statistical-analysis of spatial point patterns by means of distance methods. Biometrics 32:659-667

Dormann CF (2007) Effects of incorporating spatial autocorrelation into the analysis of species distribution data. Glob Ecol Biogeogr $16: 129-138$

Fieberg J (2007) Kernel density estimators of home range: smoothing and the autocorrelation red herring. Ecology 88:1059-1066

Fortin M-J, Dale MRT (2005) Spatial analysis: a guide for ecologists. Cambridge University Press, Cambridge

Garant D, Kruuk LEB, Wilkin TA, McCleery RH, Sheldon BC (2005) Evolution driven by differential dispersal within a wild bird population. Nature 433:60-65

Gordon DM (1997) The population consequences of territorial behavior. Trends Ecol Evol 12:63-66

Griffith DA, Peres-Neto PR (2006) Spatial modelling in ecology: the flexibility of eigenfunction spatial analyses. Ecology 87:2603-2613

Haining R (1993) Spatial data analysis in the social and environmental sciences

Heg D, Ens BJ, Van der Jeugd HP, Bruinzeel LW (2000) Local dominance and territorial settlement of nonbreeding oystercatchers. Behaviour 137:473-530

Kato T (2008) A further exploration into the robustness of spatial autocorrelation specifications. J Reg Sci 48:615-639

Kissling WD, Carl G (2008) Spatial autocorrelation and the selection of simultaneous autoregressive models. Glob Ecol Biogeogr 17:59-71

Legendre P (1993) Spatial autocorrelation-trouble or new paradigm. Ecology 74:1659-1673

Legendre P, Dale MRT, Fortin MJ, Gurevitch J, Hohn M, Myers D (2002) The consequences of spatial structure for the design and analysis of ecological field surveys. Ecography 25:601-615

Lennon JJ (2000) Red-shifts and red herrings in geographical ecology. Ecography 23:101-113
Maher CR, Lott DF (1995) Definitions of territoriality used in the study of variation in vertebrate spacing systems. Anim Behav 49:1581-1597

Makarieva AM, Gorshkov VG, Li BL (2005) Why do population density and inverse home range scale differently with body size? Implications for ecosystem stability. Ecol Complex 2:259-271

Manel S, Schwartz MK, Luikart G, Taberlet P (2003) Landscape genetics: combining landscape ecology and population genetics. Trends Ecol Evol 18:189-197

Moran PAP (1950) Notes on continuous stochastic phenomena. Biometrika 37:17-23

Schwarzer G (2009) meta: Meta-Analysis. R package version 0.9-18 http://CRAN.R-project.org/package $=$ meta

Seddon N, Amos W, Mulder RA, Tobias JA (2004) Male heterozygosity predicts territory size, song structure and reproductive success in a cooperatively breeding bird. Proc R Soc Lond Ser B Biol Sci 271:1823-1829

Sibson R (1980) The Dirichlet tessellation as an aid in data analysis. Scand J Stat 7:14-20

Smith TM, Shugart HH (1987) Territory size variation in the ovenbird - the role of habitat structure. Ecology 68:695-704

Valcu M, Kempenaers B (2008) Causes and consequences of breeding dispersal and divorce in a blue tit, Cyanistes caeruleus, population. Anim Behav 75:1949-1963

Vanpe C, Morellet N, Kjellander P, Goulard M, Liberg O, Hewison AJM (2009) Access to mates in a territorial ungulate is determined by the size of a male's territory, but not by its habitat quality. J Anim Ecol 78:42-51

Wilkin TA, Garant D, Gosler AG, Sheldon BC (2006) Density effects on life-history traits in a wild population of the great tit Parus major: analyses of long-term data with GIS techniques. J Anim Ecol 75:604-615

Worton BJ (1989) Kernel methods for estimating the utilization distribution in home-range studies. Ecology 70:164-168 